\title{
REMINISCENCES OF GIBBS BY A STUDENT AND COLLEAGUE*
}

\section{BY EDWIN BIDWELL WILSON}

When last spring I was asked to agree to give the Gibbs Lecture on this occasion, I assented on the assumption that before the time came for the lecture to be delivered I should have been entirely relieved of my executive responsibilities to the Social Science Research Council and should have had opportunity to prepare from a considerable dossier of investigations in progress a scientific paper somewhat fit to take its place with the previous lectures given in this series. As it has turned out, I have not had in full the expected relief and must appear before you with a very general talk of a personal and reminiscent nature. I will not apologize; it may well be that you prefer that type of address from me, and in view of its type I must be expected to speak without apology a good deal in the first person. After all one's personal recollections are his own; they may have little of truth in them, for memory is not infallible; to use a detached third-person style of composition may give them in appearance a greater substance of objective fact than they really merit.

To give you some appreciation of the very inadequate background with which, at the early age of twenty, I came into contact with J. Willard Gibbs, may I state that my undergraduate work was at Harvard and in mathematics, which meant pure mathematics. In the spring of 1899, Professor W. F. Osgood, with whom I had taken a number of courses and who was good enough to take a real and much appreciated interest in me, suggested that I go to Yale for my graduate work. Some of you who have a knowledge of the relative standing in pure mathematics of the departments at Harvard and Yale at that time may think the advice extraordinary. It was, but it was extraordinarily good. As Professor Osgood pointed out, I had been long enough at Harvard and had specialized sufficiently in mathematics to

* The eighth Josiah Willard Gibbs Lecture, delivered, by invitation of the Council of the Society, before the Society and the American Association for the Advancement of Science, December 30, 1930. 
get the greater part of the best Harvard had to offer in point of view, and a change would be beneficial to me.* He spoke of Pierpont and of Percey Smith whose interests were somewhat different from his own and those of Professor Bôcher with whom I had had more work than with any other than Osgood. It is my impression that neither Osgood nor Bôcher mentioned Gibbs to me. But when B. O. Peirce heard that I had decided to go to Yale he remarked that down there I might come across Gibbs "whom some of us here think a rather able fellow." Had I known Peirce then as well as I came to know him later I should have taken this remark as indicating a person of the highest quality under whom I must surely plan to study, but at the time I disregarded it entirely. I went to Yale to study with Pierpont and Smith.

How came it that I studied with Gibbs? That was one of life's minor tragedies. When I got to Yale in the autumn of 1899 and was laying out my year's work with A. W. Phillips, Dean of the Graduate School, it appeared that there were only three courses I considered worth while, whereas four were needed for full time work. Phillips suggested that I add Gibbs' Vector Analysis. I protested that according to its description it was not materially different from quaternions, of which I had had a full year under J. M. Peirce, and should hardly count as a course for me. The logic was unanswerable but the circumstances overbore it; I had to have four courses and the Dean would count Vector Analysis even though it was a sort of review; so I registered for it with a sneaking suspicion that my good master Osgood had made a mistake in sending me from a mathematically first rate institution to a second rate one. It was one of life's minor tragedies, but too late to be helped.

You are doubtless impatient that I should get along to talking about Gibbs and anxious for me to quit telling of myself; but I am just as anxious that you should realize what sort of person I was when I reached Yale after being graduated at the age of barely twenty at the head of my class with highest final honors

* This sort of generosity is not unusual at Harvard; taken with reasonably good provision for traveling fellowships, it has deprived the Harvard Graduate School of a goodly number of students of the best grade, much to the advantage of the students and of science, and thus indirectly to the advantage of the University. 
in mathematics. I was certainly immature. I was not wise enough to be confident that a new place, new contacts, new points of view have sure advantages which overbear many a technical disadvantage. I was not wise enough to know that to take a subject twice from different angles and thus better master the whole might be far better in the building of a scientific life than to be forever going on to some new subject, leaving everything both new and old with insufficient consolidation. It is not reasonable for you to suppose that, during the brief period from September 1899 when I first saw Gibbs to June 1902 when I took leave of him to go study in Paris, never to see him again, I should have matured very greatly. If I could so have failed in seeing the significance of the remark of B. O. Peirce cited above, it is certain that I must have let slip many things of importance and misinterpreted or falsely remembered many others which occurred during the period of three academic years in which I came in contact with Gibbs. You and I alike are on very insecure ground in believing anything I may recount here today.

The course on Vector Analysis was small; none of Gibbs' courses had more than a mere handful of students, four or six or possibly eight. The course was difficult for everybody in it but me, and was easy for me only because I had previously had quaternions (which incidentally I had found difficult and perplexing though I was amply prepared). The lectures followed the pamphlet which the author had printed privately in 1881-84 but had never published. There were no exercises assigned to the students to work- a truly continental type of course but embarrassing to Americans who are used even in graduate work to having the path made easy for them. The next year, thirty years ago this month, Professor Morris, editor of the Yale Bicentennial Series, asked me to prepare for that Series a text on Vector Analysis and told me that Gibbs had given his consent and that I should talk the matter over with him. The conference was short. Gibbs remarked that he had prepared his pamphlet for the convenience of his students and for distribution privately. He said that he was busy preparing a volume for the same Bicentennial Series (his Statistical Mechanics) and would not have time to advise on the composition of the Vector Analysis, to read the manuscript or the proof, that I must be entirely responsible for the whole work, that I was free to write whatever kind of 
book I pleased, to incorporate so much of his course or pamphlet as I wished and to add whatever I desired from other sources. Somewhat seriously impressed with the magnitude and lonesomeness of the task I said I would do my best, to which he kindly replied that he had confidence that I would do very well, and after the book had appeared he was good enough to remark that it was satisfactory. That is about all the contact I had with him on the Vector Analysis.

One topic which he treated at some length, but which I chose to leave out of the book was crystallography; another was the theory of orbits. The latter is adequately represented in his collected works, but the former is nowhere a matter of record and I am sorry that I omitted it, particularly as all my notes on all of Gibbs' courses were lost overboard by careless handling on the part of the crew of the steamship on which I returned from Paris in 1903 so that I had thereafter no way of reconstituting from my notes special material from his courses not found in print. One of the ablest students Gibbs had had in the nineties was G. P. Starkweather, a person as systematic as he was able. He had written out with great care his notes on Gibbs' lectures. After his early death these notes were deposited in the Yale Library. It was chiefly from a volume of these that I was able to put together that part of Gibbs' course on multiple algebra which I found it desirable to print in the Transactions of the Connecticut Academy in 1907 as a precursor to some uses I wished to make of the method in developing some geometrical theorems. I think it safe to say that the treatment of crystallography, though neat and interesting was not of any great importance except as illustrating how the methods of vector analysis could be made to convert the goniometric measures taken on crystals into the desired constants of the crystal.

At one time when Pierpont was lecturing on elliptic functions with some reference to the motion of the top, Gibbs happened to be developing by vectorial methods and discussing the physical meaning of the equations of motion of the top. He turned to the class and with the pleasant smile which of ten lighted his countenance remarked that there were those who thought the top chiefly interesting as affording an exercise in the use of elliptic functions, but that he found the top a very interesting physical object on its own account. No criticism of another was 
implied in the remark, merely an emphasis on his own point of view which he was developing to his class. Although Gibbs had purely mathematical interests as in his Vice-Presidential address on Multiple Algebra to the American Association for the Advancement of Science in 1886 and in his course on the same subject, his abiding interests were in real physical things and he rarely if ever developed his mathematical theories of physics further than was necessary to get at the important physical significance of the phenomena he was discussing; his mathematical methods were the simplest which he could devise and of ten extended little beyond close logical analysis. That was one reason his courses were hard; technical dexterity is easier than thinking. Read the great thermodynamic memoir if you desire verification of these statements.

Except in the classroom I saw very little of Gibbs. He had a way, toward the end of the afternoon, of taking a stroll about the streets between his study in the old Sloane Laboratory and his home - a little exercise between work and dinner-and one might occasionally come across him at that time. Then there were the meetings of the mathematical and the physical clubs on occasional evenings with papers read by the staff or students. I do not remember that he ever read a paper on such occasions but he was usually in attendance and apparently paying close attention; sometimes he would make very brief remarks after the speaker concluded and the penetration of those comments was noteworthy. On one such occasion when we had been hearing of the then quite new electron theory of the constitution of the atom Gibbs said that it must be getting nearly time for him to move on, that for many years he had been troubled over the problem of reconciling the number of degrees of freedom in the molecules with the value of the ratio of the specific heats at constant pressure and constant volume and that if we were to introduce all the new degrees of freedom implied by the electron constitution he would be still more at a loss. This was, of course, before the introduction of the quantum conditions.

He could be seen at faculty meetings, quiet and attentive. I do not recall hearing him speak but once, and then with few words much to the point. Once I ran across him in the library surrounded by books on the theory of numbers and reading a thesis on algebraic numbers just presented for the doctorate. 
I remarked that I had not realized that he was familiar with the theory of algebraic numbers. He replied that he was not, but that with the aid of some books he thought he might be able to come to a decision as to whether the thesis was worthy of acceptance. Once I desired to consult some books which were not in the library but which I had seen on the shelves in his office during a lecture. I ventured to ask whether I might borrow them. He was entirely willing. As I picked the books off the shelves I noticed that the pages had not been cut and enquired whether I might cut them, to which he replied: Certainly, if you think it worth while. Probably I looked abashed, for he added: The author kindly sends me all he writes; there is a great deal of it; I sometimes feel that a person who writes so much must spread his message rather thin.

There may be some interest in a letter written by Gibbs to me just a month before he died:

Dear Mr Wilson

New Haven Mch 28/03

I think that you will have next year

2 hrs Non Euclidean Geometry

2 hrs Mechanics

2 hrs Introduction to Math. Phys.

$6 \mathrm{hrs}$ Freshman, or something very like that. We will know better a little later.

I think that the reasons wh you expressed so eloquently \& I may add so discreetly to Dr. B-, would apply to an abridgment. We cannot take for granted that an abridgment wd not interfere with the sale of the larger book. The larger book is pretty heavily handicapped by its price, as it is. \& in competition with a cheaper edition could hardly hold its own. Moreover, anything requires time to be well done, \& I think to write a short book takes as much time as a longer one.

I did not mean to say that Hamilton did not have the equation

$$
q^{2}-2 S q \cdot q+(T q)^{2}=0 .
$$

He doubtless would recognize the equation as correct, \& may have written it in just that form. Only I do not see how 
he could have recognized that it is (I don't care whether you say, identical with or) analogous to the Ham. Cayley equation, because I suppose that he never was aware that a quaternion might be regarded as a matrix. I suppose that that was a discovery of the elder Peirce, as stated by Cayley in the chapter wh he wrote in Tait's 'Quaternions'.

I am glad that you find that instruction in America compares not too unfavorably with that in France. However, what you want to do is to get the best you can out of France, wh certainly will be a great addition to anything wh you may get here. I am a little surprised that you find the French Lecturers going to pieces. I had supposed that that was just what they never did-that they always gave their lectures in good form.

\section{Yours truly \\ J. Willard Gibbs}

Let me interrupt these personal reminiscences to give you a bit of history as it appears in the record. Gibbs was born on February 11, 1839. He prepared for college at the Hopkins Grammar School. He was graduated from Yale in the class of 1858 at the age of nineteen. In college his interests appear to have been Latin and mathematics as he took prizes in each in more than one year of his course. He took the Bristed Scholarship of $\$ 95$ for the best examination in Greek, Latin and Mathematics. He won the Latin Oration in both Junior and Senior years. He was awarded the Clark Scholarship of $\$ 120$ for the best examination in the studies of the college course which was conferred subject to the condition that the recipient continue as a graduate for one or two years pursuing non-professional studies. He did so continue and in 1863 got his Ph.D. degree with a thesis: "On the form of the teeth of wheels in spur gearing." In the Yale catalogs of 1863-64 and 1864-65 he is listed as Tutor in Latin; in that of 1865-66 he appears as Tutor in Natural Philosophy. Afterwards he went abroad to study. In the catalog of 1871-72 he reappears as Professor of Mathematical Physics and so continues until his death.

Except for his periods as Tutor he taught only graduate work, although particularly competent undergraduates might be admitted to his courses, especially the Vector Analysis. It may 
interest you to follow the subjects he taught. From 1871 to 1881 the topics announced were capillarity, wave theory of light and sound, least squares, and potential theory with applications to electricity and magnetism. It is not to be presumed that he taught all of these subjects in any one year, but the catalogs fail to state just which he did teach. It was in this period that the great papers on thermodynamics were published, but there is no reference to his teaching the subject. In 1881-82 he added to his list a course on Vector Analysis, having apparently not given Least Squares for some years. The list continues with minor modifications through the catalog of $1885-86$. For the year 1886-87 we find the first pretentious catalog, much larger than the preceding ones with better descriptions of the offerings. The list for Gibbs is (1) Vector Analysis, (2) Potential Theory, (3) Mathematical Theory of Electricity and Magnetism, (4) Electromagnetic Theory of Light, (5) The a priori Deduction of Thermodynamic Principles from the Theory of Probabilities, and it so continues through the year 1891-92, except for the addition of a course on the Computation of Orbits.

It is of more than passing interest that the classical thermodynamics represented by his own contributions has not appeared for the fifteen years since his paper was printed and that the first course announced by him in this field is apparently really his Statistical Mechanics on which nothing was printed until 1901. In the years $1892-94$ he apparently offered a combination of classical thermodynamics with statistical mechanics and only from 1894-95 on came to divide the work into a course on his great memoir with a supplementary one on statistical mechanics. In the meantime he had added an option in advanced vector analysis and another in multiple algebra. Thus after the middle nineties he may be considered to have run the cycle: (1) Vector Analysis, (2) Advanced Vector Analysis, (3) Multiple Algebra, (4) Thermodynamics and Properties of Matter, (5) Statistical Mechanics, (6) Electromagnetic Theory of Light, (7) Potential Theory, and Theory of Electricity. Of these (1), (4), (6) were generally two hours per week throughout the year while the others were one hour per week. He seems to have taught about six hours per week, giving (1) yearly with (4) or (6) in alternate years, and adding on occasion one or two of the other four one-hour courses. During the three years 1899- 
1902 I was fortunate enough to take all these subjects, except that the statistical mechanics (5) was not given separately, but was represented as some ten lectures at the conclusion of his thermodynamics (4).

Except for the Vector Analysis, I, in common with all Gibbs' students of my time, was ill prepared for his work. It was not infrequently the case that a student repeated the work to become more familiar with it, and it certainly was my intention to repeat most of the courses after my return from Paris. The instruction was not poor, but the concentration of thinking of the instructor was great. Once in a while Gibbs would get lost in a demonstration. He lectured without notes and what specific preparation he generally made I do not know. It was almost always some very simple affair on which he would go astray rather than something recondite. The year I took thermodynamics he could not make his Carnot engine run right. There was a tradition, perhaps unwarranted, that the Carnot engine was apt to trouble him. Sometimes he would unravel his difficulty before the end of the hour and it was then an especial treat to see his mind work; sometimes the end of the hour would come sooner and he would have to leave the matter over until the next time when he would appear with a sheet of paper containing the demonstration.

I do not believe that Gibbs kept much in the way of notes. I imagine that he wrote the closely reasoned and highly mathematical Statistical Mechanics out of his head (rather than from notes accumulated during previous years) between the time in the autumn of 1900 when he agreed to produce the book and the time in the summer of 1901 when he delivered the manuscript. The reason for this belief lies in the fewness and in the character of the papers he left when he died-therewas practically no Nachlass. And yet he was known to be working on a program of publication. I know this because of the conversation I had with him in June 1902 when I was leaving for Paris for a year's study. It was by far the longest conversation I ever had with him, and of course the last. He said that he did not wish to determine my line of future in terest but that he hoped I would consider taking some work in applied mathematics in Paris in addition to any I might take in pure mathematics. He ventured the opinion that one good use to which anybody might put a superior training in pure mathemat- 
ics was to the study of the problems set us by nature. He remarked that in the thirty years of his professorship of mathematical physics he had had but a half-dozen students adequately prepared to follow his lectures. He did me the honor to include me in the list, though I myself never felt that my preparation in physics had been adequate. I asked why he had given exclusively such advanced courses, why he had not offered some more elementary work to prepare his students. He replied that he had not felt called upon to do so but that if I were willing he would be glad to have me look forward to giving upon my return a general introductory course on mathematical physics, and at any rate he would be happy if I would bear the possibility in mind while abroad. $\mathrm{He}$ then went on to say that if I should choose to occupy myself somewhat seriously with mathematical physics he had a considerable number of problems on which he thought I could make progress and that he would be glad to talk about them on my return. How much I have regretted that he did not talk of them at the time, but he gave no inkling of them.

Finally he proceeded to say something of his own plans for the future. He remarked that if he could depend on living to be as old as Methuselah he would continue to study for several hundred years yet, but that as he could not expect any such span of years he had decided to set about preparing some matters for publication. There were three lines of activity he desired to pursue: (1) The revision and extension of his work on thermodynamics, to which he said he had some additions to make covering more recently discovered experimental facts not yet adequately incorporated into the theory and other additions of theory apparently not yet exemplified in experiment. (2) A contribution to multiple algebra on which he said he had some ideas he thought worth while even though the subject appeared at the time not to be of much interest to mathematicians, most of whom were devoting their attention to analysis. (3) A revision of his method of computing orbits which should certainly be revised now that it had recently been printed verbatim by Buchholz in the third edition of Klinkerfues' Astronomy when certain important improvements were only too obvious. He asked what I should think he had best first undertake, but without waiting for reply answered that the astronomers were conservative and unlikely to be appreciative of improvements in his methods for 
orbits, that the mathematicians were not impatient to learn of his ideas in multiple algebra and that on the whole he felt it was more important to set about the work in thermodynamics to which he had made no published contribution of significance for about twenty-five years.

Ten months later, in April 1903, Gibbs died. There were found among his papers some chapter headings and the first beginnings of text on the revision and extension of his thermodynamic work. It was clear that what he intended to accomplish he carried in his head and not on paper. We shall never know what he had in mind in any of the three lines of activity. He waited and studied too long. This situation is primarily that on which I base my opinion that he wrote the Statistical Mechanics out of his head in something like nine months in addition to his regular teaching. The task was serious. All through the winter and spring of 1900-1901 he worked not only by day, the light in his study in Sloane could be seen burning at night. The manuscript was finished in the summer at Intervale, N. H. After Gibbs died A. W. Phillips told me that it was this severe work that killed him. He said that they had gone together to the express office to dispatch the copy to Scribners, that up to that time Gibbs had been quite himself but that from the time they turned away from the office he slumped, the elasticity was gone from his gait, he was a worn out old man, and never fully came back.

This is a thrilling story but sad. However, it may not be true. I communicated it to my old friend Ralph Van Name, nephew of Willard Gibbs, who writes: "This may be true, but it was not apparent to his family," and later, "my comment on the incident of the delivery of the manuscript of the Statistical Mechanics was not made in a spirit of criticism, but merely as a statement of my recollection, and of that of my sister, whom I had consulted about it. Though both of us were in Europe at the time of Willard Gibbs' death, I did not leave New Haven until June 1902, and she not until March 1903. It is unquestionably true that my uncle worked to the limit of his strength in trying to get the volume finished on time, and that he did not get over the effects for a good while. But both of us have the impression that he seemed to be in practically normal health and spirits by the autumn of 1901. ... My uncle's final illness 
was a sudden and acute attack of a nature which has no obvious connection with his overwork two years before-it was an intestinal obstruction which the doctors were unable to relieve." I may say that all through the academic year 1901-2 Gibbs seemed to me to be in normal condition, and in his conversation of June 1902 of which I have given so long an account seemed to be looking cheerfully and healthily ahead with real pleasure in the prospect which he was outlining and with no discernible feeling that it might not be finished-indeed he spoke as one surely counting on being active on my return fifteen months later.

If I have gone at such length into this story I have done so chiefly because it so well illustrates stories which come with the best intention of truth from persons near to Gibbs, with just as high desires to tell the truth and nothing but the truth as I have on this occasion, but which none the less cannot be wholly credited, quite as I do not wholly credit as fact my own statements. There is the story that at home, where he lived all his life with his sister who had married his friend and classmate Addison Van Name, he always insisted on mixing the salad on the ground that he was a better authority than the others on the equilibrium of heterogeneous substances. A very pretty conceit, and one vouched for by a colleague much closer to Gibbs than I, but I daresay both the fact and the statement of reason for the fact would not be substantiated by the family. Another story refers to his letter to Nature in comment on and disproof of Lord Kelvin's proposed experiment to determine the velocity of longitudinal waves in the ether. It is said that when a colleague told him that he had just seen the letter in print Gibbs blushed and said that he could not believe the Editor of Nature would print it. That illustrates his modest and retiring disposition, which was a conspicuous trait, but seems hardly credible.

One often hears lament at Yale and elsewhere that Gibbs' colleagues did not capitalize his great discoveries in physical chemistry by developing the subject experimentally and intensively in New Haven from 1876 on. The comment often takes the turn of wondering how much greater role American science would have played in the growth of physical chemistry if Gibbs had accepted the offer to go to the Johns Hopkins University instead of remaining at Yale. How much difference would it 
have made? Perhaps very little. What efforts Gibbs made to develop physical chemistry at Yale I do not know; perhaps none. That he knew his thermodynamic work was important and knew so when he printed it I have no doubt; but I have noted above that he appeared not to have lectured upon it in his cycle of courses for about 15 years after its completion, preferring for some reason to teach other subjects, and the subject matter of the memoir is not such as would be likely to diffuse around any university without exposition by the master unless by chance there were at hand some almost equally competent person who very much needed the work as a basis for his own, and knew that he needed it. Gibbs was not an advertiser for personal renown nor a propagandist for science; he was a scholar, scion of an old scholarly family, living before the days when research had become résearch. Probably he had faith that when the time was ripe for his thermodynamics, the doctrine would spread.

Another beautiful legend is that Gibbs was not appreciated in this country or at Yale during his life. It is probably true that his name was not well known to the ordinary Yale alumnus before the recent time when his photograph and some eulogy of him were widely circulated to the alumni during a drive for funds. But the efforts which were made to arrange for printing his long and costly paper in the Transactions of the Connecticut Academy in 1876-78 were a high testimonial to the faith of his local contemporaries in his work. He was elected to the $\mathrm{Na}$ tional Academy at 40 , the average age of election being 50 , and only the year after the appearance of the second half of the thermodynamic memoir. In 1881 he received the Rumford Medal from the American Academy of Arts and Sciences which means that a group of his contemporaries in Boston appreciated promptly and highly his contributions in the field of heat. Of course he did not have the notice which Einstein receives today; he had no press agents and surely wanted none. There seems to be every evidence that he received the type of recognition to be expected.

Whether the establishment of the Gibbs Lectureship by the American Mathematical Society should be ranked as one of the honors to his memory or whether it belongs with the circularizing of his photograph to Yale alumni as an attempt to get some- 
thing through exploiting his name I will not venture an opinion. It is well known that this Society through all of its life has been chiefly in control of those interested in research in pure mathematics. It is also well known that the group of American students who went to Germany to study mathematics in the late eighties and early nineties, at the very time when Klein was emphasizing the need in Germany of a greater attention to applied mathematics, came back to this country with a determination to promote only pure mathematics. This may have been wise at the time. American mathematicians had been too exclusively interested in the applications. We needed emphasis, perhaps temporarily over-emphasis, on pure theory and rigorous procedures, on analysis as it had developed in Europe. The lengths to which this emphasis was carried may be illustrated by my telling a story which happened not so long ago. When E. W. Brown, a past president of this Society, was at last naturalized as an American citizen and thus became eligible for election to our National Academy of Sciences, I asked one of the leaders in the section of mathematics of that Academy and also a leader in this Society whether the mathematicians would not nominate Brown to the Academy. He replied in a breezy vernacular "Not till Hell freezes over"-Brown was to him not a mathematician, but Brown is here in good company with Gibbs and G. W. Hill, H. A. Newton, Newcomb and others. Another story shows how non-mathematicians were impressed with this point of view. I once met at the Cosmos Club an eminent expert in international relations who asked why I happened to be in Washington. I replied "To attend the meeting of the $\mathrm{Na}$ tional Academy of Sciences." "But," said he, "you are a mathematician not a scientist," and added, "oh, yes, I remember now that it is an academy of the sciences and of mathematics."

The mathematician has a dilemma, a choice. Insofar as he turns his attention to the abstract theory of his subject he is not a scientist dealing with observed fact but a philosopher playing with a priori hypotheses. It is only when he turns his attention to applied mathematics that he becomes a scientist. With the obvious need of specialization today, I would not limit the choice of the individual mathematician; he should be free to follow his bent or the exigencies of the institution he serves. A great national mathematical society, however, should not limit 
its interests, it should cover the whole field of mathematics both pure and applied. In doing so it puts itself right on the pinnacle of intellectual effort. There is no problem requiring more brains, sounder judgment, better total adjustment internal and external, then that of uniting the logical and operational techniques of pure mathematics with the infinite variety of observable fact which Nature offers to our contemplation with a ringing challenge to our best abilities. It was in this field that Gibbs was supreme. He had studied with Weierstrass and was not unmindful of mathematical rigor; in the paper in which he pointed out that phenomenon of the convergence of Fourier series which has come to be known as the Gibbs phenomenon he showed his appreciation of mathematical precision as he did on other occasions. But fundamentally he was not interested in rigor for itself, he was inspired by the greater problem of the union between reflective analytical thought and the world of fact. He did not feel that one should not study pure mathematics; he was not one-sided or dogmatic in any of his views. What he said was that one of the uses of a good mathematical background was in the study of the problems set us by Nature. And if I had one special inference to draw from my contact with him to give you today it would be that the American Mathematical Society should follow for its own good his judgment on that matter. There are indeed indications that times are somewhat changing and that in the future the mathematics in which you as a Society are interested will be all mathematics, pure and applied. When that time comes there will be no possibility of raising the query as to whether the Gibbs Lectureship may be only lip service to a great name, for it will be evident that the thought of this Society is itself in no small measure a constant testimonial to that great thinker, J. Willard Gibbs.

You may be somewhat disappointed that I have no very striking personal reminiscences to recount, but what should you really expect in the way of impressions gained by an immature young fellow in the early twenties of a mature quiet scholar 40 years his senior? Gibbs was not a freak, he had no striking ways, he was a kindly dignified gentleman. I came to his courses in the days prior to tutorial systems when students were not expected to take the time of their teachers outside the classroom for personal contact and when teachers did not feel a moral urge 
to guide their students otherwise than by instruction given in course. I am not sure but this was better for both student and teacher even if it has resulted in a less picturesque address today than one which some now twenty-year-old at the California Institute of Technology could give thirty years hence about Millikan.

School of Public Health, HARVARD UNIVERSITY 